\title{
Per oral endoscopic myotomy (POEM) for all spastic esophageal disorders?
}

Authors

Institutions
Sabine Roman ${ }^{1,2}$, Mathieu Pioche ${ }^{2,3}$, François Mion ${ }^{1,2}$

'Digestive Physiology, Hospices Civils de Lyon and Lyon I University, Lyon, France

${ }^{2}$ LabTau, INSERM, U1032, Lyon, France

${ }^{3}$ Gastroenterology, Hospices Civils de Lyon and Lyon I University, Lyon, France submitted

20. December 2014

accepted after revision

28. December 2014

\section{Bibliography}

DOI http://dx.doi.org/

10.1055/s-0034-1391417

Published online: 7.5.2015

Endosc Int Open 2015; 03: E202-E204

(C) Georg Thieme Verlag KG Stuttgart · New York

E-ISSN 2196-9736

\section{Corresponding author}

Sabine Roman, MD

Digestive Physiology

Hôpital Edouard Herriot

5, Place d'Arsonval

69437 Lyon Cédex 03

France

Fax: +33-4-72-11-01-47

roman.sabine@gmail.com

\section{License terms}

(ब) (1) $\Theta \circledast$
Achalasia is a rare esophageal motility disorder defined as impaired relaxation of the esophagogastric junction (EGJ) and the absence of esophageal peristaltic contractions. High resolution manometry (HRM) is now the gold standard for the diagnosis of achalasia. Pandolfino et al. proposed classifying achalasia into three subtypes based on esophageal contraction patterns on HRM [1]. In the most recent iteration (version 3.0) of the Chicago Classification of esophageal motility disorders on HRM, achalasia is defined as impaired EGJ relaxation and subsequently divided into three subtypes [2]. Type I is characterized by the absence of esophageal contractions and the absence of pressurization, type II by the absence of esophageal contractions and at least $20 \%$ of swallows that are associated with panesophageal pressurization, and type III (also called spastic) by at least $20 \%$ of contractions that are premature ( $\bullet$ Fig. 1a-c). Different studies demonstrated the clinical relevance of this classification [3-6]. Thus, patients with type II achalasia had the best outcome overall after treatment, whereas patients with type III had the worst.

The response to treatment may also differ according to the performed procedure. Rohof et al. observed that outcome was better in patients with type III achalasia who underwent laparoscopic Heller myotomy (LHM) than in those who underwent pneumatic dilation [5]. One simple explanation would be that pneumatic dilation alleviates only EGJ obstruction, whereas LHM not only alleviates EGJ obstruction but also may treat spastic contractions (which are associated with EGJ obstruction in type III achalasia) by extending the myotomy along the distal esophagus.

The popularity of per oral endoscopic myotomy (POEM) for the treatment of achalasia is rapidly growing. First described in 1980 by Ortega et al. [7], the procedure was developed later by Inoue et al., who used the submucosal flap technique as a safe transmural approach [8]. Since 2010, different series have reported the safety and efficacy of the procedure [9-13]. In this issue of Endoscopy International Open, Kumbhari et al. have evaluated the efficacy of the POEM procedure in 49 patients with type III achalasia [14]. Patients at eight different centers were retrospectively included, and their results were compared with those of 26 patients who underwent LHM at a single center. A clinical response, defined as an Eckhardt score of 1 or lower, was more frequently observed in the patients treated with POEM than in those treated with LHM (98.0\% vs. 80.8\%; $P<0.01$ ).

As demonstrated by Kumbari et al., POEM may be an attractive procedure for patients with type III achalasia. The fact that endoscopic myotomy can be started more than $10 \mathrm{~cm}$ above the EGJ may explain why it may be more efficient for treating type III achalasia, which is associated with abnormal contractions in the mid and distal esophagus. However, the results of this retrospective study must be interpreted with caution because the endoscopic myotomy technique probably varied from one center to another. Thus, the effect of the exact length of the myotomy, and the effect of a myotomy limited to the internal muscular layer versus that of a full-thickness myotomy, cannot be correctly evaluated based on these results.

When HRM is used, hypercontractile esophageal motility disorders are classified into two categories: distal esophageal spasm (DES), in which at least $20 \%$ of contractions are premature (contractions occurring within a phase when esophageal contractile activity is normally inhibited), and jackhammer esophagus, in which at least $20 \%$ of contractions occur with extreme vigor (contractions with a distal contractile integral $>8000$ mmHg.s.cm) [2] ( $\bullet$ Fig.1d,e). These disorders, never encountered in normal individuals, are responsible for esophageal symptoms (mainly dysphagia and chest pain) $[15,16]$. 

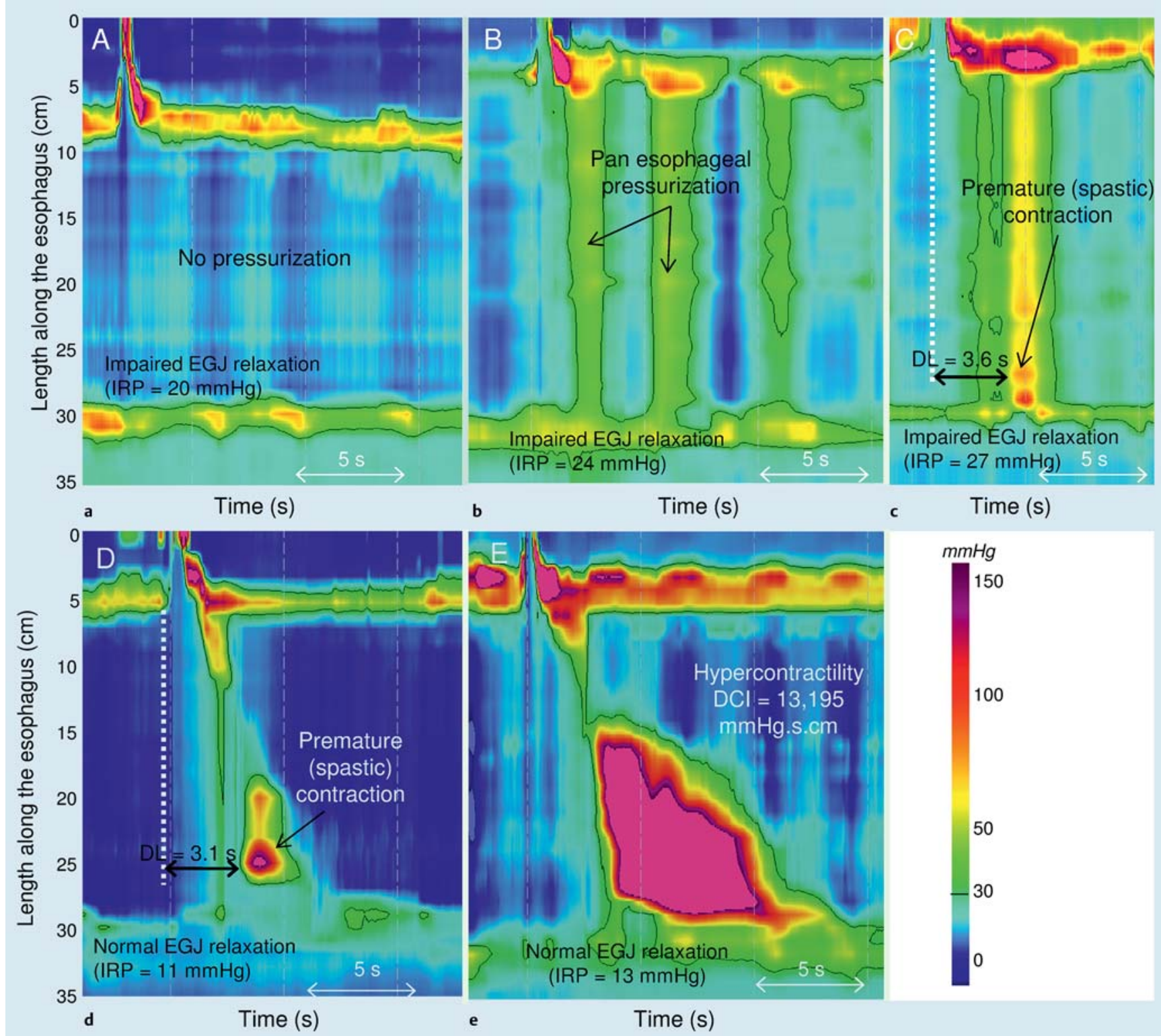

Fig. 1 Esophageal motility disorders on high resolution manometry. Achalasia is characterized by impaired esophagogastric junction (EG]) relaxation (defined as an integrated relaxation pressure [IRP] $>15 \mathrm{mmHg}$ ). Esophageal pressurization is absent in type I achalasia (a), at least $20 \%$ of swallows are associated with pan-esophageal pressurization in type II (b), and at least $20 \%$ of contractions are premature (that are contractions with a distal latency [DL] of < 4.5 seconds) in type III (c). Distal esophageal spasm (d) is defined as normal EG] relaxation and at least $20 \%$ of contractions that are premature, and jackhammer esophagus is defined as at least $20 \%$ of swallows that are hypercontractile (that are contractions with a distal contractile integral [DCl] $>8000 \mathrm{mmHg} .5 . \mathrm{cm})(\mathbf{e})$.

Treating these disorders is challenging: pharmacologic treatment (nitrates, calcium channel blockers) is disappointing, botulinum toxin injection has short-term efficacy, and surgical extended myotomy may require a thoracoscopic approach [17]. POEM is a promising therapeutic approach because it is possible to start the submucosal tunnel and subsequent myotomy in the proximal esophagus, allowing a significant modification of muscular activity in the esophageal body with a minimally invasive approach. In this study, Kumbhari et al. clearly showed that the complication rate was not higher and the procedure duration was no longer with POEM than with LHM, despite a longer myotomy [14]. Case reports and small series have reported the efficacy of POEM for hypercontractile esophageal motility disorders [1823]. However, a recent series suggested that the outcome after the POEM procedure may be better in patients with achalasia than in those with DES or jackhammer esophagus [24]. Complete relief of dysphagia was observed in $98 \%$ of patients who had achalasia versus $71 \%$ of patients with esophageal motility disorders that were not achalasia. Future controlled studies are required to evaluate the place of POEM in patients with spastic esophageal disorders and to determine the optimal length of myotomy in treating these disorders.

Competing interests: S.R. and F. M. have served as consultants for Given Imaging; M. P. has no competing interest to declare. 


\section{References}

1 Pandolfino JE, Kwiatek MA, Nealis T et al. Achalasia: a new clinically relevant classification by high-resolution manometry. Gastroenterology 2008; 135: 1526-1533

2 Kahrilas PJ, Bredenoord AJ, Fox $M$ et al. The Chicago Classification of esophageal motility disorders, v3.0. Neurogastroenterol Motil 2015; 27: $160-174$

3 Pandolfino JE, Ghosh SK, Rice J et al. Classifying esophageal motility by pressure topography characteristics: a study of 400 patients and 75 controls. Am J Gastroenterol 2008; 103: 27-37

4 Pratap $N$, Kalapala $R$, Darisetty $S$ et al. Achalasia cardia subtyping by high-resolution manometry predicts the therapeutic outcome of pneumatic balloon dilatation. J Neurogastroenterol Motil 2011; 17: $48-53$

5 Rohof WO, Salvador R, Annese $V$ et al. Outcomes of treatment for achalasia depend on manometric subtype. Gastroenterology 2013; 144: $718-725$

6 Salvador R, Costantini M, Zaninotto $G$ et al. The preoperative manometric pattern predicts the outcome of surgical treatment for esophageal achalasia. J Gastrointest Surg 2010; 14: 1635-1645

7 Ortega JA, Madureri V, Perez L. Endoscopic myotomy in the treatment of achalasia. Gastrointest Endosc 1980; 26: 8-10

8 Inoue $H$, Minami $H$, Kobayashi $Y$ et al. Peroral endoscopic myotomy (POEM) for esophageal achalasia. Endoscopy 2010; 42: 265 - 271

9 Familiari P, Gigante G, Marchese $M$ et al. Peroral endoscopic myotomy for esophageal achalasia: outcomes of the first 100 patients with short-term follow-up. Ann Surg 2015: Epub 2014 Oct 30

10 Hungness ES, Teitelbaum EN, Santos BF et al. Comparison of perioperative outcomes between peroral esophageal myotomy (POEM) and laparoscopic Heller myotomy. J Gastrointest Surg 2013; 17: 228 - 235

11 Swanstrom LL, Kurian A, Dunst CM et al. Long-term outcomes of an endoscopic myotomy for achalasia: the POEM procedure. Ann Surg 2012; 256: 659-667

12 Von Renteln D, Fuchs KH, Fockens $P$ et al. Peroral endoscopic myotomy for the treatment of achalasia: an international prospective multicenter study. Gastroenterology 2013; 145: 309-311.e1-3

13 Ren Z, Zhong Y, Zhou P et al. Perioperative management and treatment for complications during and after peroral endoscopic myotomy
(POEM) for esophageal achalasia (EA) (data from 119 cases). Surg Endosc 2012; 26: $3267-3272$

14 Kumbhari V, Tieu A, Onimaru $M$ et al. Peroral endoscopy myotomy vs laparoscopic Heller myotomy for the treatment of type III achalasia in 75 patients: a multicenter comparative study. Endoscopy International Open 2015: DOI 10.1055/s-0034-1391668 [Epub 2015]

15 Pandolfino JE, Roman S, Carlson D et al. Distal esophageal spasm in high-resolution esophageal pressure topography: defining clinical phenotypes. Gastroenterology 2011; 141: 469-475

16 Roman S, Pandolfino JE, Chen J et al. Phenotypes and clinical context of hypercontractility in high resolution pressure topography (EPT). Am J Gastroenterol 2012; 107: 37-45

17 Roman S, Kahrilas PJ. Distal esophageal spasm. Dysphagia 2012; 24 : $115-123$

18 Minami H, Isomoto $H$, Yamaguchi $N$ et al. Peroral endoscopic myotomy (POEM) for diffuse esophageal spasm. Endoscopy 2014; 46: E79-E81

19 Khashab MA, Saxena P, Kumbhari V et al. Peroral endoscopic myotomy as a platform for the treatment of spastic esophageal disorders refractory to medical therapy (with video). Gastrointest Endosc 2014; 79: $136-139$

20 Louis H, Covas A, Coppens E et al. Distal esophageal spasm treated by peroral endoscopic myotomy. Am J Gastroenterol 2012; 107: 19261927

21 Shiwaku $H$, Inoue $H$, Верpu $R$ et al. Successful treatment of diffuse esophageal spasm by peroral endoscopic myotomy. Gastrointest Endosc 2013; 77: 149-150

22 Kandulski A, Fuchs KH, Weigt J et al. Jackhammer esophagus: high-resolution manometry and therapeutic approach using peroral endoscopic myotomy (POEM). Dis Esophagus 2015: DOI 10.1111/ dote.12182 Epub 2014 Jan 27

23 Kristensen HO, Bjerregaard NC, Rask P et al. Peroral endoscopic myotomy (POEM) for nutcracker esophagus. Three cases with 12 months follow-up. Scand J Gastroenterol 2014; 49: 1285-1289

24 Sharata AM, Dunst CM, Pescarus $R$ et al. Peroral endoscopic myotomy (POEM) for esophageal primary motility disorders: analysis of 100 consecutive patients. J Gastrointest Surg 2015; 19: 161 - 170 